\title{
Another look at travel patterns and urban form: The US and Great Britain
}

\section{Genevieve Giuliano*}

School of Policy, Planning and Development

RGL 216

University of Southern California

Los Angeles, CA 90089-0626

Phone 213-740-3956

Fax 213-740-0001

giuliano@usc.edu

Dhiraj Narayan

School of Policy, Planning and Development

University of Southern California

Los Angeles, CA 90089-0626

*Contact Author 


\section{Summary:}

This paper explores the relationship between land use patterns and individual mobility from a comparative international perspective. There is a vast literature on US automobile dependence. Major explanatory factors include: transportation, housing, land use and tax policy; per capita incomes; American cultural preferences; national geography; and spatial structure of US metropolitan areas (itself a result of the first three factors). Emphasizing the policy environment, many researchers have cast their analysis in comparative terms, noting the differences in automobile use between European countries and the US. It is argued that US patterns of metropolitan form, with low development densities and dispersed population and employment, reinforce auto dependence. In contrast, most European metropolitan areas, with higher densities and more centralized land use patterns, have lower levels of auto use. Stronger controls on land use employed in many European countries are seen as having preserved the compact form of metropolitan areas. These arguments imply significant relationships between land use patterns and travel behavior. Using travel diary data from the US and Great Britain, we compare these relationships across the two countries. We find that differences in daily trips and miles traveled are largely explained by differences in household income. High density is associated with less travel in the US, but not in Great Britain, likely the result of greater spatial concentration of low income households in the US and higher quality public transport in Great Britain. 


\section{Introduction}

The relationship between transportation and land use continues to be of great interest to urban researchers across many disciplines. This relationship is also a public policy issue of growing importance. Automobile dependence is a major topic in sustainability discussions, and it is linked to the growth of dispersed, low density patterns of urban development. This paper explores the relationship between land use patterns and individual mobility from a comparative international perspective. Using individual travel diary data for the US and Great Britain, we present some preliminary results on travel patterns and their relationship with basic measures of urban form.

\section{Literature Review}

There is a vast literature on US automobile dependence. Decades of research by geographers, economists, historians, and others have generated a widely accepted set of explanations for the US situation (e.g. Muller 1981; Pucher, 1988; Jackson 1985). Major factors explaining US auto dependence include: 1) transportation, housing, land use and tax policy, 2) per capita incomes, 3) American cultural preferences, 4) national geography, and 5) spatial structure of US metropolitan areas (itself a result of the first three factors). The major emphasis has been on the policy environment. Many researchers have cast their analysis in comparative terms, noting the differences in automobile use between European countries and the US (Dunn, 1981; Pucher, 1988; Pucher and Lefevre, 1996; Nivola, 1999). Pucher (1988), for example, provides a list of the key policies that affect the price and convenience of auto ownership and use. Recent research has focused on the role of land use patterns. 
It is argued that US patterns of metropolitan form, with low development densities and dispersed population and employment, reinforce auto dependence. In contrast, most European metropolitan areas, with higher densities and more centralized land use patterns, have lower levels of auto use. It is argued that stronger controls on land use employed in many European countries have preserved the compact form of metropolitan areas (Cervero, 1995; Bernick, and Cervero 1997; Pucher and Lefevre, 1996; Newman and Kenworthy, 1998). Of course, land use patterns are the outcome of historical development patterns, which are in turn a function of policy, economic factors, technology, and culture.

However, when we compare trends over time, we find that automobile ownership and use is increasing in both the US and in Europe, and that the rate of increase over the past two decades has been greater in several European countries than in the US (Giuliano, 1999; Orfeuil and Salomon, 1993; Pucher and Lefevre, 1996). In addition, urban growth patterns in Europe are showing forces of decentralization, with central cities losing employment share, and more rapid growth occurring in suburbs (Gillespie,1999; Hansen,1993). That is, countries with far different policy environments than the US are experiencing the same phenomena, albeit from a very different base and under different economic and social circumstances.

Trends of the past two decades call into question our conventional understanding of auto dependence. Countries with far less "auto friendly" land use patterns, and with policies that make auto use much more costly and impose far more control on land use patterns are experiencing continued growth in auto ownership and 
use. A cross national projection of car ownership by Dargey and Gately (1997) show a continuation of substantial increases in car ownership in most European countries but relatively little increase for the US.

Trend data suggest that policy factors may not be as important as once thought. Transportation economists have long argued that per capita income is the single most important explanatory factor in auto ownership and use (Meyer and Gomez-Ibanez, 1981; Lave, 1996; Ingram and Liu, 1999). The effectiveness of policies that affect the price of auto ownership and use declines as relative income increases. Value of time increases with income, effectively offsetting the higher monetary costs of faster modes and increasing demands for such modes. In addition, economic restructuring has changed firm location patterns in response to shifts in agglomeration benefits (spread of agglomeration economies over greater spatial distances due to reduced transport and communications costs), and the shift to an information-based economy allows more activity to be "footloose" (Kasarda, 1995; Chinitz, 1991; Kutay, 1988a, 1988b). Moreover, the ability of governments to impose constraints on auto ownership and use may decline as globalization proceeds and location freedom increases.

Although there are many international studies of travel patterns, these do not explicitly address transportation and land use relationships. ${ }^{1}$ International comparative research on transportation and land use has to date been limited either to aggregate comparisons using national data or to qualitative discussions. Aggregate comparisons include the various Newman and Kenworthy studies (1989a, 1989b, 1998). These 
studies compare per capita gasoline consumption and metropolitan densities, and find a non-linear relationship of increasing per capita gasoline consumption with declining density. Their work has been criticized, primarily because per capita fuel consumption is an indirect measure of auto travel, and because they fail to account for many other factors that affect automobile use, such as the employment rate or household size (Gordon and Richardson, 1989; Gomez-Ibanez, 1991). Schafer and Victor (1998) presented a travel budget model with time and money constraints, and showed that these are stable over space and time. They projected future levels of mobility and modal use across 26 countries. Their work does not address land use factors and is based on national averages.

Pucher and Lefevre (1996) provide an overview of travel trends across several European countries, and discuss differences in terms of policy, geography and cultural factors. Among the numerous and complex factors that may account for differences, they note the greater proportion of population living in central cities, more restrictive land use and automobile policies, and a greater consensus among voters and politicians to control the negative impacts of the automobile. Nivola, (1999) explains the sprawl of US metropolitan areas vs compact urban form of European countries by 13 "determinants" ranging from national geographic and demographic differences to differences in tax policy. Giuliano (1999) describes travel and land use trends in the US and several European countries, and argues that rising per capita incomes, changing demographics, and economic restructuring explain trends in travel patterns in

\footnotetext{
${ }^{1}$ For example, see Orfeuil and Salomon, 1993.
} 
both the US and Europe. An exception to these mainly descriptive studies is the Clark and Kupers-Linde (1994) comparison of commuting patterns between the Los Angeles Metropolitan Area and the Randstaad region of The Netherlands. Comparing shifts in commuting patterns over time, Clark and Kupers-Linde show that commute flows have lengthened and dispersed in both metropolitan regions (despite very different policy environments). These shifts are attributed to economic restructuring and the emergence of polycentric spatial form.

Comparisons across national aggregates ignore within-country variations that might be important explanatory factors. For example, some countries are more urbanized than others, or have older population age profiles, and both these factors are known to affect travel behavior. In addition, aggregate patterns are the outcomes of individual decisions regarding where, when, how and with whom to conduct daily activities. Hence understanding differences in aggregate travel patterns requires understanding differences in disaggregate travel patterns.

\section{Research Approach}

In examining the role of land use factors, what is the appropriate measure of travel? In a previous paper (Giuliano 2002), we have argued that appropriate measures should capture travel for all purposes and by all modes. Total travel can be measured in terms of trips, distance and time. Trips capture the total number of activities conducted, but provide limited information. The more interesting question is where people choose to shop or work. The spatial range of travel over the course of the day is 
captured by distance and time. Of these, distance is the more appropriate measure of mobility.

Travel time is problematic, because it is determined by both distance and speed. Higher travel speed is better, all else equal, as it reduces the time cost of traveling a given distance. Nonetheless, low travel speed may indicate spatial forms (mainly high density development) that provide higher levels of accessibility, and may provide additional insight on transportation - land use relationships. In this paper, however, we restrict the analysis to total daily trips and total daily travel distance.

Our basic question is, what explains differences in travel patterns - particularly automobile use - between the US and the countries of Europe? More specifically, what is the role of land use characteristics? The literature shows that travel is a function of individual and household characteristics, household transportation resources (car availability, driver's license), transportation prices and supply characteristics, and land use. If we assume that individuals are rational utility maximizers, it follows that similar people should have similar behavior, all else equal. For example, household income or the individual's age should have a consistent relationship to travel across the two countries. However, cultural differences may promote differences. For example, if older adults are more likely to live with extended family in Europe, we might expect lower levels of trip making, since household maintenance activities are shared among more people.

Car availability is mainly a function of the costs of ownership and use. Possession of a driver's license a function of the historical trajectory of car ownership. 
In many European countries women are less likely than their US counterparts to have a driver's license, and the difference increases with age. Transportation supply and price characteristics should work the same way across individuals, but differences between countries should lead to comparable differences in travel patterns. Prior research has shown that higher costs of car purchase, fuel and parking are associated with relatively less car use. Land use is considered a major factor, as the distribution of activities in space determines accessibility. Higher densities in European metropolitan areas should be associated with relatively less car use and more use of public transit and nonmotorized modes. Similarly, the greater availability of public transport in large metropolitan areas, together with congestion and higher parking costs, should be associated with less car use.

The present research addresses mobility, or the total amount of travel a given person conducts over the course of a day, by all modes, both motorized and not motorized. The general model is,

$$
Y=f(X, T, L)
$$

Where

$Y=$ daily mobility

$X=$ attributes of the individual

$T=$ transportation resources available to the individual

$L=$ attributes of the residential location 
The $X$ variables include the main characteristics associated with travel, such as age, gender, employment status, household composition, and household income. Transportation resources include driver's license and car availability. Location attributes include density and metropolitan location. How should country differences be incorporated into this model? The question is whether observed differences between countries remain, once socio-economic and geographic factors are controlled. We use dummy variables to test both independent and first order interaction effects. The model to be estimated is therefore:

$$
Y=f(X, T, L, X R, T R, L R, R)
$$

$$
\text { Where } \boldsymbol{R}=\text { country dummy. }
$$

What about differences in transportation supply and pricing? We know that indicators such as road mileage or fuel prices differ greatly across countries, and these differences will be picked up by the country dummy variable. The question is, are differences within each country so large that these factors should be taken into account? At this time suitable data are not available at the regional level, hence we leave this question for subsequent analysis.

There is also a question regarding how car ownership should be incorporated into the model. Car ownership depends on price as well as demand for travel, and 
hence is endogenous to daily mobility. Therefore a simple OLS regression model based on (2) above will be biased. One way to avoid this problem is to estimate a reduced form model, omitting car ownership variables. On the other hand, we could argue that daily travel is the outcome of short-run decisions, given a series of longer run choices about car ownership, employment and residential location, hence it is reasonable to include car ownership variables in the model. In this paper we present results for both approaches.

\section{Data}

International comparisons must begin with the fundamental question of what to compare. In our case the decision was made for practical reasons. We want to eventually include several European countries in our research, but the difficulties of generating comparable data sets constrained us to beginning with just one European country, Great Britain. We had access to travel diary data and to the government staff who managed the survey. We were therefore able to work through the many challenges of understanding the data and making the necessary changes to generate comparable data sets. From an analytical standpoint, Great Britain represents a reasonable representation of a "European country," in that widespread car ownership occurred well after World War II, its central cities are dense, pedestrian oriented and well served by public transit, auto ownership and use costs are relatively high, and land use controls are relatively strong. It is also important to note the large fundamental 
differences between the two countries in terms of population, size, and household income, as illustrated in Table 1.

\section{The NPTS and NTS}

We use the US 1995 Nationwide Personal Travel Survey (NPTS) and the UK 1995/97 National Transport Survey (NTS). Both are household-based surveys that elicit travel diary information from all members of the household. ${ }^{2}$ The NPTS was conducted for the first time in 1969 to develop a database of basic travel information for the US. Households are selected via a complex stratified sampling method, and all members five years old or older of the selected households are interviewed. Information on household characteristics, individual characteristics, car ownership and use is collected. The 1995 NTPS included 42,000 households, of which half are from states or metro areas that paid to have their area over-sampled. Households were assigned a 24 hour "travel day" and a 14 day "travel period". The survey data are weighted to account for sample design and selection probability, non-response bias and non-coverage bias. $^{3}$

The NTS is a series of household surveys designed to provide a national bank of personal travel information for Great Britain. The Ministry of Transport

\footnotetext{
${ }^{2}$ Specifically, all persons 5 years or older are included in NPTS; all persons of all ages are included in NTS.

${ }^{3}$ The weighting is developed for households. The household weights are based on time of year, geographic region, race/ethnicity, and household size. Person weights are calculated from the household weight, adjusted for non-responding members of responding households. Trip weights are calculated based on the person weights. The weights are scaled to the total US 1995 population.
} 
commissioned the first NTS in 1965. The NTS is based on a random sample of private households, and is limited to Great Britain (England, Wales, Scotland). In order to select the appropriate number of addresses, a stratified multi-stage random probability sample is used. Seven day travel diaries are kept by each member of the household, with adults reporting for younger children and others unable to provide information on their own behalf. Data collected include information on: household, individuals, vehicles, long-distance journeys (including those made in the three weeks before the start of the seven day travel week), journeys made during the travel week, and stages of journeys made during the travel weeks. The NTS makes a special effort to include 'short walks', e.g. walks trips of less than 1 mile. Respondents are asked to include these trips on Day 7 of the diary only. The NTS data are not weighted. The sample is presumed representative of the population based on the way the sample is chosen. The NTS is conducted on an ongoing basis; the "1995" survey was conducted from 1995 through early 1997 . The NTS sample included 9,688 "fully co-operating" households in 1995/1997. ${ }^{4}$ Basic characteristics of the two samples are given in Table 2.

After extensive data cleaning and adjustments to assure comparability across the two samples, we created a pooled sample randomly drawn from the two surveys. Preliminary analysis revealed that using only the Day 7 NTS data was the best alternative for generating comparable person level travel diary files. ${ }^{5}$ Once these files were created, we drew random samples from each file to generate a 50/50 pooled

\footnotetext{
4 A fully cooperating household has completed all basic survey questions and each household member has completed the 7 day diary.

${ }^{5}$ See Giuliano, Hu and Narayan (2000) for details.
} 
sample. Because of the difference in sample size, the selection ratio was 1 in 9.5 for the US and 1 in 2.3 for GB. The US sample was drawn from the weighted file, and weights were preserved in the pooled sample. We use the 1995 OECD purchasing power parity of 0.6539 to convert GB household income data to US dollar values. ${ }^{6}$

\section{Measures of Urban Form}

Empirical research is often constrained by data availability. Much of the literature on urban form, for example, is based on measures of population because population data is widely available. Comparative research is typically even more constrained because of the difficulties involved in obtaining data in comparable spatial units. For these reasons we are limited to two measures of urban form: metropolitan size and population density. Metropolitan size is a rough proxy measure of accessibility and urban structure. Smaller metropolitan areas (those under 500,000 population) tend to be self-contained, with one main center. Larger metro areas are more likely to polycentric and hence have more cross-commuting. The largest metro areas, particularly those with large downtowns, have the greatest potential for high levels of daily travel due to long average commutes and high accessibility over an extensive area. In contrast, non-metropolitan areas may be very self-contained (there is nowhere to go outside one's village), or many generate fewer but longer trips due to very limited accessibility. Metropolitan size is measured in the US by Metropolitan Statistical Area (MSA) and by Consolidated Metropolitan Statistical Area (CMSA).

\footnotetext{
${ }^{6}$ http://www.oecd.org/std/pppoecd.xls
} 
For Great Britain, we developed a comparable measure by using 1991 British Census population figures and the household residence location data.

In the US, population density, when measured at a sufficiently disaggregate level, has proven to be an effective proxy for intra-metropolitan spatial structure (e.g. Pushkarev and Zupan, 1977; Niemeier and Rutherford, 1994; Schimek, 1996). High density is a surrogate for greater transit availability, more walkable environments, mixed use, and high accessibility. Low density is a surrogate for low accessibility. Population density may not be as useful a measure for Great Britain, given the generally greater availability of what might be termed high "local accessibility" areas. We measure density at the most disaggregate level possible with our data. For the US, the spatial unit is the census tract; the spatial unit for GB is the Local Area, generally larger than US census tracts.

\section{Sample Characteristics}

There are substantial differences between the US and GB in demographic and socio-economic characteristics. The age distribution for GB has both more children (expected due to including children of all ages in the sample) and a larger share of older persons. There are relatively more persons in two or more adult households with children in the US, but more multiple adult households without children in GB. There are also relatively more multiple adult retired households in the US. Household income is much lower in GB, as was shown in Table 1. All of these differences suggest lower rates of travel for GB, all else equal. 
There are also differences in residential location patterns. A much larger share of the US sample lives in low density residential environments, as expected. In contrast, a larger share of the GB sample lives in very high density environments (see Figure 1). Sample distributions across metropolitan area size are given in Table 3. About 40 percent of the GB sample lives in smaller urban areas or rural areas, compared to just 14 percent for the US. ${ }^{7}$ The largest share of the US sample lives in the largest MSAs (over 1 million), with almost 40 percent of the sample in MSAs of over 3 million (see Table 3). Note that these differences are due in part to the large differences in the size and population of the two countries. Greater London is the only metropolitan area in Great Britain with population greater than 3 million. Given the data on population density, it is reasonable to conclude that large US MSAs include a lot of low and medium density development. Again, these differences suggest relatively lower travel rates for GB persons.

Table 4 illustrates the very large differences in car ownership patterns between the two countries. About three-fourths of the US sample reside in households with at least as many cars (POVs) as drivers; just over half of the GB sample live in such households. In contrast, about one fourth of GB persons live in households with no car, and an additional quarter live in households where the number of drivers exceeds the number of cars available. It is important to note that our numbers are calculated on the basis of persons, and hence are not comparable to published data based on households.

\footnotetext{
${ }^{7}$ Data compatibility problems prevent us from further distinguishing these categories.
} 


\section{RESULTS}

Results are presented in two parts. First, we give some basic descriptive statistics on travel characteristics. Then we present results from regression models.

\section{Travel Characteristics}

We begin by presenting some descriptive information on travel characteristics. The results in this section are based on the full separate samples. Table 5 gives average daily person trips, travel distance, and travel time. The basic measure of travel - trips -- is much lower for GB. Not only do the British make fewer daily trips, they are more likely to not have traveled at all on the survey day, despite the greater attention paid in the NTS survey to very short trips. About one fifth of the British sample did not travel on Day 7, compared to 16 percent for Americans. Note that if there is any bias in the trip numbers, it is to underestimate short trips in the US sample. Hence differences may be even larger than these numbers indicate.

On average, Americans travel twice as far as the British, but spend only a few more minutes per day traveling. The relative consistency in time spent traveling is the basis of travel budget theory: people have a fixed time budget for travel, and the cost and speed of available modes determine number of trips and travel distance. In this case, we might interpret the significantly lower British rate of travel a response to limited transportation resources. As would be expected, US average trip length is 
much longer (7.5 miles vs 4.8 miles for GB), but average trip time is shorter (15.2 minutes vs 18.9 minutes for GB). See Figure 2.

Distribution of trips by purpose is also different. Work or work related trips and personal business trips make up a larger share for Americans, while social/recreational trips make up a smaller share, relative to the British. The greater share of these trips in the GB sample may be due to more complete reporting of very short walk trips.

Modal shares (based on total person trips) are given in Table 6. Differences are dramatic. First, about 89 percent of all US person trips are made by privately owned vehicle (POV), while the combined share of private vehicle trips for GB is about 58 percent. Second, within the POV category, the big difference is in driver trips. Because of the way trips are recorded, there is no direct way to determine vehicle occupancy (what may or may not be a multi-person trip). However, the share of driver trips is an indicator of vehicle occupancy; obviously a much larger share of US trips is drive alone trips. Second, the transit share is under 2 percent in the US, but around 8 percent for GB. Third, use of non-motorized modes is more than four times as frequent in GB as in the US. Such trips account for about one third of all trips. Recalling again the emphasis of the NTS on short trips, the non-motorized share for US may be biased downward.

As has been noted in numerous studies (e.g. Dunn, 1981; Pucher, 1988; Orfeuil and Salomon, 1993), a major explanatory factor for these differences is the difference in the cost of owning and operating an automobile. The combined effects of the VAT 
and sales tax add about 25 percent to the price of a new automobile in Great Britain, compared to sales taxes of 5 to 8 percent in the US. In 1999, the price of petrol and diesel in Great Britain was the highest in the European Union, a result of the UK's unique fuel tax escalator (Mitchell and Lawson, 2000). Figure 3 gives per liter gasoline costs by year for the US and UK, in ppp (purchase power parity) equivalents. The UK price has risen from $\$ 0.25$ per liter in 1970 to $\$ 0.90$ per liter in 1995 . Over the same period the US price increased from $\$ 0.10$ to $\$ 0.30$. Thus the difference in gasoline prices between these countries has quadrupled in the 25 year period.

\section{Regression Model Results}

We estimated two sets of regression models, one with trips as the dependent variable, the other with distance, using the pooled sample. Our control variables include sex, age, household income, and employment status. All are coded as categorical dummy variables. Previous research indicates that this small set of control variables is adequate. We use as a measure of car access the ratio of cars to drivers in the individual's household. Admittedly this measure has a US "bias": we assume that the car is the preferred mode, and when there are fewer cars than drivers, some household members will choose other modes or will forego a trip. Under some conditions, it is possible that the car is not the preferred mode.

\section{$\underline{\text { Total Daily Trips }}$}

Starting with trips, Table 7 gives results for the full model, and Table 8 gives

results for the reduced form model. Coefficients and standard errors are given for the 
total sample in the first panel of numbers; the same data are given for the Great Britain interaction terms in the second panel. We use a conservative measure of statistical significance. $^{8} \quad$ The estimations were conducted using stepwise regression. The last column gives the F-test significance level for each additional group of variables. Each row of coefficients provides comparisons between the US and Great Britain, with comparisons being relative to the US. The effect for British persons is the sum of the values of the two coefficients. Because the independent variables are category dummies, the relative magnitude of the coefficients may be directly interpreted.

Considering first the group of socio-economic characteristics, we find that sex has no significant relationship with total daily trips. Children and older people make fewer trips, as expected; income and employment effects are also as expected. Only one of the interaction dummy variable coefficients is significant, meaning that overall, these socio-economic factors work the same way in both countries (more precisely, we cannot reject the null hypothesis that there are no differences between the two groups). The one significant income interaction dummy coefficient suggests that for GB, trip rates between the two middle income groups are more similar, and trip rates between the third and highest groups are less similar than is the case for the US (recall that the income groups are based on equivalent incomes).

We use as a measure of car access the ratio of cars to drivers in the individual's household. As expected, individuals with no car in the household have the lowest trip

\footnotetext{
8 The complex weighting procedure employed in the NPTS sample creates statistical difficulties in conducting inference tests. To minimize these problems, we use a stricter
} 
rates relative to the omitted category (cars $=$ drivers), and the effect is quite pronounced. The effect of having fewer cars than drivers is also negative, but of much smaller magnitude. Again, there is no difference in the effects of car access between Great Britain and the US.

We use two measures of urban form, metropolitan location and population density in the place of residence. We do not expect urban form measure to have much influence on trip rates; influence should be greater on travel distance. Possibly trip rates are lower in very inaccessible places and higher in very accessible places. Table 6 shows that the smaller MSAs are associated with more trip making relative to larger MSAs. Residing in very high density areas is associated with less trip making relative to lower density areas. In the US, this may be explained by the relatively high share of low income households residing in high density areas, but this may not be the case for Great Britain. Note that none of the interaction dummy variable coefficients are significant, either individually or as a group, meaning that these measures of urban form have no different relationship with trip making between the two countries.

Finally, the Great Britain dummy coefficient is significant and negative as expected. The dummy captures the many differences between the two countries not explicitly controlled for in the model. Given the much lower average trip rate of the British sample, the value of the coefficient is somewhat low.

Table 8 gives results for the reduced form model. Results are quite similar. The Great Britain dummy coefficient is greater in magnitude, as are the income and

significance level. See Giuliano (2002) for further discussion. See NPTS Users Guide, 
employment variable coefficients. This makes sense: the car ownership effects are now captured by these variables. As before, there are few differences between the US and British sample with respect to socio-economic variables. Results for the urban form variables are quite similar to those for the full model, with the exception of high density, which increases in magnitude. This may be due to correlation between household income and density in the US data, as well as a "New York effect", meaning the relatively low rate of car ownership in the highest density areas.

We may summarize the results of the trip regressions as follows. First, the models explain very little of the variation in trip making. Also, these models are quite simple, while the differences between trips on various modes and for various purposes are quite substantial. Second, basic socio-economic characteristics are important explanatory factors and work the same way in both countries. Hence some of the difference we observe between the US and Great Britain is due to lower household income and different population demographics. Third, our urban form variables have little effect on trip making for either group. The relationship between high density and less trip making is a US phenomenon and may to be linked to the spatial distribution of the low income population. Finally, the pooled model has about the same explanatory power for both groups. Separate regressions yield a comparable $\mathrm{R}^{2}$ (results not shown). 


\section{$\underline{\text { Total Daily Miles Traveled }}$}

Tables 9 and 10 give model results for total daily travel distance. Because the distribution of the dependent variable is skewed towards long distances, we use the natural $\log$ form. ${ }^{9} \quad$ Starting with the full model (Table 8 ), the socio-economic variable coefficients are mostly significant and of the expected sign (first panel). More miles traveled is associated with male sex, adult age, higher household income, and being employed. Only one of the interaction dummy coefficients is significant: third quartile income. As with the trip results, this suggests more similarity between the two middleincome groups for the British. The British dummy variable coefficient is of the expected sign, but not significant. Given that the British on average travel half as many daily miles as the Americans, this is somewhat surprising.

Greater car access is associated with more daily travel distance, as expected, with the coefficient for no cars in the household of greatest negative magnitude. Results for the interaction terms are interesting: the positive coefficient for cars less than drivers is consistent with public transport playing a more important role in Great Britain. The greater availability and higher quality of public transport in Great Britain makes it a closer substitute to the car than in the US. When people have discretionary income to spend on transportation, one can purchase more public transport and achieve a relatively high level of mobility.

Turning to metropolitan size, none of the coefficients for the total sample are significant, though there is a suggestion of a pattern of more daily miles in the larger 
MSAs. The interaction coefficients are all negative, and three are significant. It is difficult to interpret these results, given the very different distributions of the two groups across metropolitan size categories (see Table 3).

The most interesting results are those for residential density. Two of the three coefficients for the total sample are significant and of the expected sign. However, coefficients for the interaction variables are also significant and of the opposite sign. The combined effect indicates that there is no relationship between daily travel distance and density among the British. We would expect that given the higher relative price of motorized travel, the British would be more inclined to economize and therefore make shorter trips in more accessible places. ${ }^{10}$ There are two possible explanations for these results. First, the greater availability and higher quality of transit may provide a more uniform level of transport access across levels of density. Second, mixed patterns of land use are widespread, and consequently population density may be a less useful measure of urban form in Great Britain. That is, the higher price of travel promotes economizing everywhere, and land use patterns make such economizing possible. Recall that the British density measure is more aggregate than that of the US, so very high or very low density is lost in the aggregation. Thus our measure could have the effect of underestimating the relationship.

The reduced form results in Table 9 are similar to those of the full model. As with the trip regressions, the income and employment coefficients are somewhat

\footnotetext{
${ }^{9}$ Specifically, we use $\operatorname{Ln}($ distance +0.1$)$ to retain persons with zero trips in the regression.
} 
greater in magnitude. There is a more negative effect for the low-income interaction term, likely reflecting the large proportion of no car households in this category. The metropolitan size variable coefficients are largely unchanged; the high-density coefficient becomes more negative, again reflecting the concentration of US lowincome households in the highest density areas.

\section{Conclusions}

We draw the following conclusions from our results. First, there are few differences in the way that socio-economic and urban form characteristics are associated with travel patterns between the US and Great Britain. With few exceptions, sex, age, household income and employment status have similar effects. Therefore observed differences between countries are in part explained by differences in population characteristics, notably lower household income for the British.

Second, car access is a powerful explanatory force for both trip making and travel distance. Individuals residing in households with no cars make significantly fewer daily trips and travel significantly fewer miles, all else equal. We noted earlier that car access might not work the same way in Great Britain, as we would expect more households to choose not to own cars, given the greater availability of public transit and high access neighborhoods. The reduced effect of fewer cars than drivers (essentially one car households) for the British is consistent with this hypothesis.

\footnotetext{
${ }^{10}$ Deregulation and privatization have resulted in relatively high fares for public transport, compared to typical US transit fares.
} 
When we remove the car access variables from the model, income and employment effects increase in magnitude, as expected.

Third, metropolitan size has a small but significant relationship with trips, but not with travel distance. It is difficult to explain the results for daily trips, since there is no obvious reason why trip frequency should be a function of metropolitan size. It is possible that more and shorter trips take place in smaller, more self-contained metro areas. We expected more effects for travel distance. As we noted earlier, large MSAs provide accessibility across large spatial areas, so there are relatively more opportunities for longer distance trips. In addition average journey-to-work trip length increases with metropolitan size.

Fourth, while residential density has the expected relationship with travel distance for the US sample, there is no relationship between density and travel distance for the British sample, once other relevant factors are controlled. We speculate that this may reflect more use of transit in the highest density British areas, and may even reflect something of a "London effect" - most of the highest density zones are in Central London, where transit service is particularly extensive. The results may also reflect the greater concentration of low-income households in high-density areas in the US. In any case, these results lend little support to the idea that more compact urban form leads to less travel distance. More research is certainly in order on this question.

Our literature review discussed various perspectives on the differences in travel patterns between the US and Europe. One perspective emphasized policy differences, which, together with historical development and technological change, have led to 
more compact urban environments and higher costs for automobile use in Europe. Another perspective emphasizes household income, arguing that auto ownership and use is largely a function of per capita income. Our results tend to support the latter perspective: socio-economic characteristics are significant and generally consistent across the two countries. Results for our land use measures are more mixed.

Our research suffers from some obvious limitations. First, we have used just two simple measures of urban form; ideally one would include a more direct measure of accessibility, and better measures of metropolitan spatial structure. We are currently in the process of developing better measures of urban form. It is also argued that the spatial characteristics that matter are highly localized neighborhood characteristics, e.g. local access to shops and services, pedestrian friendly streets. Hanson and Schwab's Swedish study (1987) shows the significance of local accessibility; later work by others has yielded more mixed results (Boarnet and Crane, 2001). Unfortunately, data limitations preclude such comparisons across the two countries.

Second, we have not directly incorporated prices or measures of transportation supply (e.g. access to transit, road supply). Given a two-country comparison, price effects are incorporated in the country dummy variable. However, transportation supply must have significant within country variation (consider transit access in the US), yet we have implicitly assumed within-country homogeneity. These supply effects are incorporated in the country dummy variable (and to some extent in the urban form measures) along with all the other unmeasured --many not measurable-differences between the two countries. Third, some would argue that we are using 
measures of travel that are too aggregate. The choice process may be different across trip purposes, for example. We argue that it is appropriate to use measures of total mobility in this type of study, though there is much to be learned from more targeted analysis. Finally, our reduced form model is a very basic way to address the endogeneity problem; a two-stage approach allowing car ownership choice to be modeled explicitly might yield better results. Despite these limitations, however, our results provide a starting point for systematic comparative analysis of travel patterns and urban form.

\section{Acknowledgement}

This research was supported by the General Motors Foundation, the USC School of Policy, Planning, and Development, and by the USC Lusk Center for Real Estate. Research assistance was provided by graduate students Dhiraj Narayan, His-Hwa Hu, and Hyung-Cheal Ryu. Lee Schipper, University of California, Berkeley, provided the NTS survey data and collaborated on development of the data sets and descriptive analysis of the data. Ms. Barbara Noble and Mr. Darren Williams, Department of Environment, Transport, and the Regions, UK, assisted with NTS data preparation. Comments from participants at the ITS Seminar (Berkeley, CA, September 2001), the STELLA Focus Group 5 meeting (Brussels, April 2002), Joyce Dargay and Peter Gordon are greatly appreciated. All errors and omissions are the responsibility of the authors. 


\section{References}

Bernick, M. and R. Cervero (1997) Transit Villages in the 21st Century, McGraw-Hill, New York.

BoARnet, M. and R. CRANE. (2001) Travel by Design. New York: Oxford University Press.

Cervero, R. (1995) "Planned communities, self-containment and commuting: A crossnational perspective, Urban Studies, Vol. 32, No. 7, 1135-1161.

CHINITZ, B. (1991) "A framework for speculating about future urban growth patterns in the U.S., "Urban Studies, 28(6), 939-959.

Clark, W.A.V. and M. KuPERS-Linde (1994) Commuting in restructuring Urban regions, Urban Studies V31-3 p465-84.

Dargay, J and D. Gately, (1997), "Income's Effect on Car and Vehicle ownership, Worldwide: 1960-2015" Transportation Research 33A(7/8), 101-138.

DunN, J (1981) Miles to go: European and American Transportation policies. MIT press: Cambridge, MA.

GILLESPIE, A. (1999) "The changing employment geography of Britain," in M Breheny (ed) The People: Where Will They Work?, Town and Country Planning Association, London.

GiUlianO, G. (2002) "Travel, location and race/ethnicity," Transportation Research A, forthcoming.

Giuliano G., H-H Hu and D. NARAYAn (2000) “International Travel Project” Working Paper 1. Unpublished; available from the author. University of Southern California, Los Angeles.

GiUlianO, G. (1999) "Land use and transportation: Why we won't get there from here," Transportation Research Circular, 492, 179-198.

Gomez-IBAnez, J. A. (1991) "The Political Economy of Highway Tolls and Congestion Pricing" Paper presented at the Seminar on the Application of Pricing Principles to Congestion Management, Federal Highway Administration, Washington, D.C. 
Gordon, P. and H.W. Richardson (1989) Gasoline Consumption and Cities - A Reply. Journal of the American Planning Association, 55, 342-346.

Hansen, G.R.M (1993) Commuting: Home sprawl, job sprawl, traffic jams. In A Billion Trips a Day: Tradition and Transition in European Travel Patterns, eds. I. Salomon, P. Bovy and J.P. Orfeuil. Kluwer Academic Publishers, Dordrecht, The Netherlands, 101-127.

HANSON, S. and M. SChWAB. (1987) “Accessibility and Intraurban Travel.” Environment and Planning A, 19: 735-748.

InGRAM, G.K. and Z. LIU (1999) "Determinants of Motorization and Road provision" in Essays in Transportation Economics and Policy. Brookings Institution Press, Washington.

JACKSON, K. (1985) The Crabgrass Frontier. Oxford University Press, New York.

KASARDA, J. (1995) "Industrial restructuring and the challenging location of jobs". In State of the Union, ed. R. Farley. Russel Sage Foundation, New York.

KuTAY,A. (1988a) Technological change and spatial transformation in an information economy:1. A structural model of transition in the urban system. Environment and Planning A 20. 569-593.

KUTAY,A. (1988b) Technological change and spatial transformation in an information economy:2. The influence of new information technology on the urban system. Environment and Planning A 20. 707-718.

LAVE, C. (1996) Are Americans really driving so much? Access 8, 14-17.

Meyer, J And J.A.Gomez-IBANEZ (1981) Auto Transit and cities. A twentieth century fund report. Harvard University Press: Cambridge, MA.

Mitchell, C. AND S. Lawson (2000) The Great British Motorist 2000.

Muller, P. (1981) Contemporary Suburban America. Englewood Cliffs, NJ: Prentice-Hall.

Newman, P. and J. Kenworthy (1998) Sustainability and Cities: Overcoming Automobile Dependence. Washington, DC: Island Press. 
Newman, P. and J. Kenworthy (1989a) "Gasoline consumption and cities". Journal of the American Planning Association Winter: 24-37.

Newman, P. and J. Kenworthy (1989b) Cities and Automobile Dependence: An International Sourcebook. Brooksfield Vt: Gower Technical.

NiEMEIER, D. and RUTHERForD (1994). Non-Motorized Transportation, NPTS: Travel Mode Special Reports, U.S. Department of Transportation, Federal Highway Administration, Office of Highway Information Management, Washington, D.C.

Nivola, P. S. (1999) Laws of the Landscape: How Policies Shape Cities in Europe and America Washington, DC: Brookings Institution Press Washington.

ORfEuil, J.P. and I. SAlOMON (1993) “Travel Patterns of the Europeans in every day life”. In $A$ billion Trips a Day: Tradition and transition in European Travel Patterns, eds. I. Salomon, P. Bovy and J.P. Orfeuil. Kluwer Academic Publishers, Dordrecht, The Netherlands.

PuCher John and C. LefeVre. (1996) The Urban Transport Crisis - in Europe and North America. Great Britain: McMillan Press Ltd.

PuChER, JOHN (1988) Urban Travel Behavior as the outcome of public policy. Journal of the American Planning Association 54(3), 509-519.

PushKareV, B. and J. ZuPAN (1977) Public Transportation and Land Use Policy. Bloomington: Indiana University Press.

Schafer, A. and D. G. Victor (1997) "The Future Mobility of the World Population”. Discussion Paper 97-6-4, Massachusetts Institute of Technology, Center for Technology, Policy, and Industrial Development, Cambridge, MA.

SchimeK, PaUl. (1996). "Household Motor Vehicle Ownership and Use: How Much Does Residential Density Matter?" Transportation Research Record 1552: 120-25.

Zahavi Y, and A. TAlvitie (1980). Regularities in travel time and money expenditures, Transportation Research Record 750: 13-19. 


\section{List of Tables}

Table 1. Basic Statistics, US And UK

\begin{tabular}{lll}
\hline & US & UK \\
\hline Population (2000 est.) & $275,500,000$ & $59,500,000$ \\
Land Area (km2) & $9,158,960$ & 241,590 \\
Median Household Income (ppp, 1999) & $\$ 33,900$ & $\$ 21,800$ \\
\hline
\end{tabular}


Table 2. Basic Sample Characteristics

\begin{tabular}{lll}
\hline & NPTS & NTS \\
\hline Total households & 42,033 & 9,688 \\
Total persons & 95,360 & 23,167 \\
Total trips & 409,025 & $377,560^{\mathrm{a}}$ \\
\hline a Full seven-day file & &
\end{tabular}

a Full seven-day file 
Table 3. Place of residence metropolitan area size, share of persons, percent

\begin{tabular}{lll}
\hline & NPTS 1995 & NTS 1995 \\
\hline Not in MSA & 14.4 & 40.6 \\
$100 \mathrm{~K}-250 \mathrm{~K}$ & 9.6 & 9.1 \\
$250 \mathrm{~K}-500 \mathrm{~K}$ & 6.4 & 24.8 \\
$500 \mathrm{~K}-1 \mathrm{M}$ & 12.7 & 3.0 \\
$1 \mathrm{M}-3 \mathrm{M}$ & 18.8 & 10.7 \\
$>3 \mathrm{M}$ & 38.1 & 11.5 \\
\hline
\end{tabular}


Table 4. Car Access, persons

\begin{tabular}{lll}
\hline & \multicolumn{1}{c}{ NPTS 1995 } & NTS 1995 \\
\hline No car in HH & 3.0 & 23.2 \\
Cars $<$ drivers & 17.0 & 25.8 \\
Cars = drivers & 64.0 & 48.0 \\
Cars $>$ drivers & 16.0 & 3.0 \\
\hline
\end{tabular}


Table 5. Average Daily Person Trips, Travel Distance, Time

\begin{tabular}{lccccc}
\hline & \multicolumn{2}{c}{ US } & \multicolumn{2}{c}{ GB } \\
\cline { 2 - 6 } & Mean & Median & Mean & Median \\
\hline Trips/day & 3.8 & 4.0 & 2.9 & 2.0 \\
Miles/day & 28.7 & & 17.0 & 14.0 & 6.0 \\
Minutes/day & 58.4 & & 46.0 & 54.4 & 40.0 \\
Share no trip days & & 16.0 & & 21.0 & \\
N & & 95360 & & 23167 \\
\hline
\end{tabular}


Table 6. Modal shares

\begin{tabular}{lll}
\hline & US & GB \\
\hline POV driver & 63.1 & 37.1 \\
POV passenger & 26.1 & 21.1 \\
Bus & 1.2 & 6.6 \\
Rail & 0.5 & 1.6 \\
Bike/walk & 6.8 & 32.3 \\
Other & 2.3 & 1.3 \\
$\mathrm{~N}$ & 395157 & 66737 \\
\hline
\end{tabular}


Table 7. Dependent variable: trips/day, full model

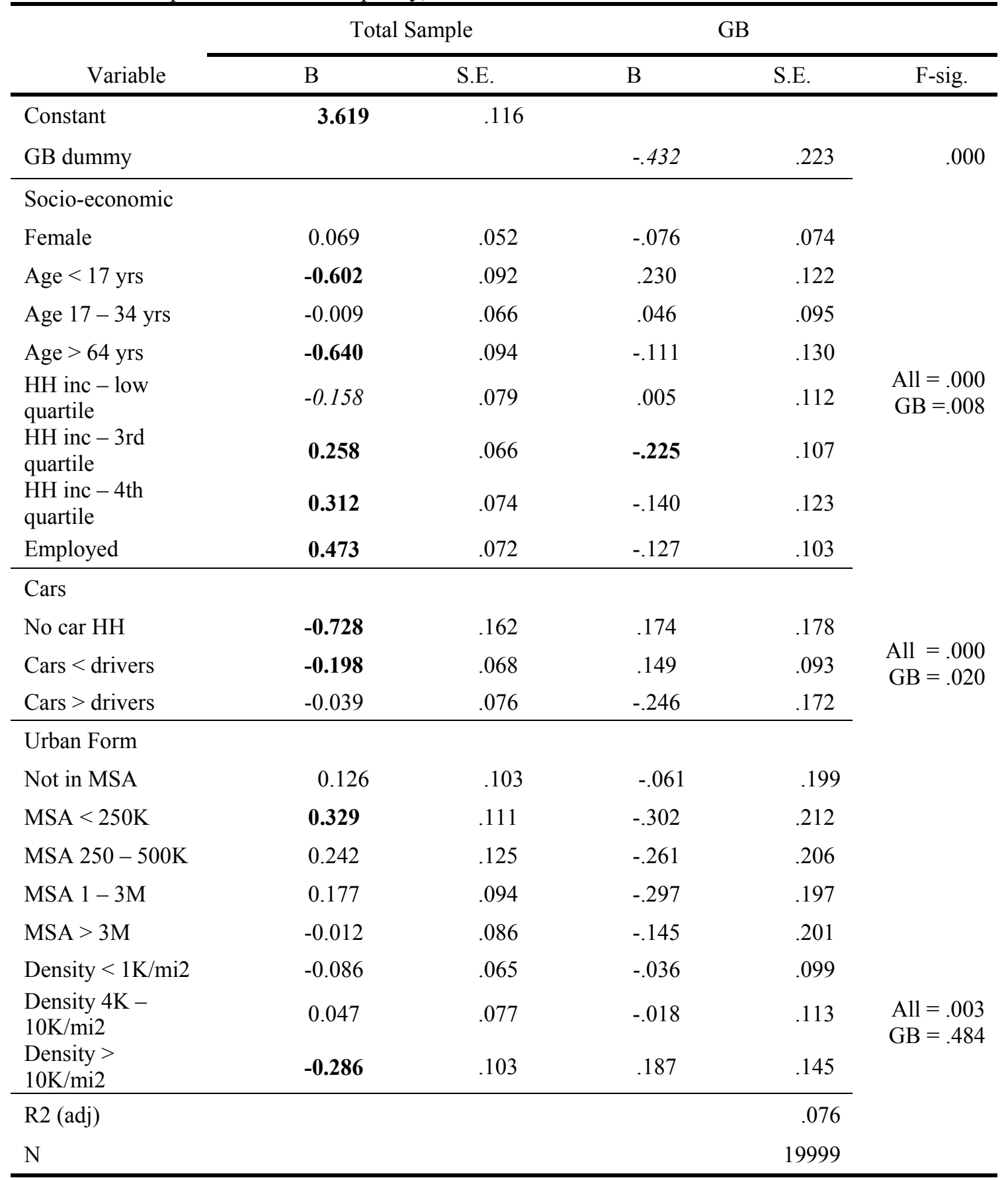

Bold $=$ sig. At $\mathrm{p} \leq .01$

Italic $=$ sig. At $\mathrm{p} \leq .05$ 
Table 8. Dependent Variable: Trips/Day, Reduced Form Model

\begin{tabular}{|c|c|c|c|c|c|}
\hline \multirow[b]{2}{*}{ Variable } & \multicolumn{2}{|c|}{ Total Sample } & \multicolumn{2}{|c|}{ GB } & \multirow[b]{2}{*}{ F-sig. } \\
\hline & B & S.E. & B & S.E. & \\
\hline Constant & 3.552 & .114 & & & \multirow{10}{*}{$\begin{aligned} \mathrm{All} & =.000 \\
\mathrm{~GB} & =.008\end{aligned}$} \\
\hline GB dummy & & & -.538 & .220 & \\
\hline \multicolumn{6}{|l|}{$\begin{array}{l}\text { Socio- } \\
\text { economic }\end{array}$} \\
\hline Female & .070 & .052 & -.096 & .074 & \\
\hline Age $<17$ yrs & -.599 & .089 & .243 & .123 & \\
\hline $\begin{array}{l}\text { Age } 17-34 \\
\text { yrs }\end{array}$ & -.018 & .066 & .028 & .095 & \\
\hline Age $>64$ yrs & -.630 & .094 & -.164 & .130 & \\
\hline $\begin{array}{l}\text { HH inc - low } \\
\text { quartile }\end{array}$ & -.205 & .079 & -.097 & .110 & \\
\hline $\begin{array}{l}\text { HH inc-3rd } \\
\text { quartile }\end{array}$ & .278 & .066 & -.233 & .107 & \\
\hline $\begin{array}{l}\text { HH inc }-4 \text { th } \\
\text { quartile }\end{array}$ & .335 & .074 & -.149 & .123 & \\
\hline Employed & .484 & .072 & -.082 & .103 & \\
\hline \multicolumn{6}{|l|}{ Urban Form } \\
\hline Not in MSA & .126 & .103 & .036 & .199 & \multirow{6}{*}{$\begin{aligned} \mathrm{All} & =.000 \\
\mathrm{~GB} & =.231\end{aligned}$} \\
\hline $\mathrm{MSA}<250 \mathrm{~K}$ & .326 & .111 & -.224 & .213 & \\
\hline $\begin{array}{l}\text { MSA } 250- \\
500 \mathrm{~K}\end{array}$ & .242 & .126 & -.172 & .206 & \\
\hline MSA $1-3 \mathrm{M}$ & .187 & .094 & -.227 & .197 & \\
\hline $\mathrm{MSA}>3 \mathrm{M}$ & -.018 & .087 & -.082 & .202 & \\
\hline $\begin{array}{l}\text { Density < } \\
1 \mathrm{~K} / \mathrm{mi} 2\end{array}$ & -.074 & .065 & -.026 & .099 & \\
\hline $\begin{array}{l}\text { Density } 4 \mathrm{~K}- \\
10 \mathrm{~K} / \mathrm{mi} 2\end{array}$ & .034 & .077 & -.008 & .113 & \multirow[t]{3}{*}{$\begin{aligned} \mathrm{All} & =.000 \\
\mathrm{~GB} & =.212\end{aligned}$} \\
\hline $\begin{array}{l}\text { Density }> \\
10 \mathrm{~K} / \mathrm{mi} 2\end{array}$ & -.404 & .101 & .266 & .143 & \\
\hline R2 (adj) & & & & .072 & \\
\hline $\mathrm{N}$ & & & & 19999 & \\
\hline
\end{tabular}

Bold $=$ sig. At $\mathrm{p} \leq .01$

Italic $=$ sig. At $\mathrm{p} \leq .05$ 
40

GENEVIEVE GIULIANO ET AL

Table 9. Dependent Variable: Ln(Miles/Day), Full Model

\begin{tabular}{|c|c|c|c|c|c|}
\hline \multirow[b]{2}{*}{ Variable } & \multicolumn{2}{|c|}{ Total Sample } & \multicolumn{2}{|c|}{ GB } & \multirow[b]{2}{*}{ F-sig. } \\
\hline & B & S.E. & B & S.E. & \\
\hline Constant & 1.700 & .091 & & & \\
\hline GB dummy & & & -.143 & .176 & .000 \\
\hline \multicolumn{6}{|l|}{ Socio-economic } \\
\hline Female & -.177 & .041 & -.040 & .058 & \\
\hline Age $<17$ yrs & -.059 & .070 & -.154 & .097 & \\
\hline Age $17-34$ yrs & -.092 & .052 & .071 & .075 & \\
\hline Age $>64$ yrs & -.475 & .074 & -.002 & .103 & \\
\hline $\begin{array}{l}\text { HH inc - low } \\
\text { quartile }\end{array}$ & -.129 & .063 & -.055 & .088 & $\begin{aligned} \mathrm{All} & =.000 \\
\mathrm{~GB} & =.002\end{aligned}$ \\
\hline $\begin{array}{l}\text { HH inc-3rd } \\
\text { quartile }\end{array}$ & .254 & .052 & -.162 & .084 & \\
\hline $\begin{array}{l}\text { HH inc }-4 \text { th } \\
\text { quartile }\end{array}$ & .292 & .059 & .150 & .097 & \\
\hline Employed & .862 & .057 & -.089 & .081 & \\
\hline \multicolumn{6}{|l|}{ Cars } \\
\hline No car HH & -.782 & .128 & -.051 & .141 & \multirow{3}{*}{$\begin{aligned} \mathrm{All} & =.000 \\
\mathrm{~GB} & =.000\end{aligned}$} \\
\hline Cars $<$ drivers & -.334 & .054 & .248 & .073 & \\
\hline Cars $>$ drivers & -.047 & .060 & -.191 & .136 & \\
\hline \multicolumn{6}{|l|}{ Urban Form } \\
\hline Not in MSA & -.024 & .081 & -.117 & .158 & \multirow{5}{*}{$\begin{aligned} \mathrm{All} & =.001 \\
\mathrm{~GB} & =.072\end{aligned}$} \\
\hline $\mathrm{MSA}<250 \mathrm{~K}$ & .093 & .088 & -.403 & .168 & \\
\hline $\begin{array}{l}\text { MSA } 250- \\
500 \mathrm{~K}\end{array}$ & .122 & .099 & -.351 & .162 & \\
\hline MSA $1-3 \mathrm{M}$ & .049 & .074 & -.292 & .155 & \\
\hline $\mathrm{MSA}>3 \mathrm{M}$ & .118 & .068 & -.446 & .159 & \\
\hline $\begin{array}{l}\text { Density < } \\
1 \mathrm{~K} / \mathrm{mi} 2\end{array}$ & .267 & .051 & -.342 & .078 & \multirow{5}{*}{$\begin{aligned} \mathrm{All} & =.000 \\
\mathrm{~GB} & =.000\end{aligned}$} \\
\hline $\begin{array}{l}\text { Density } 4 \mathrm{~K}- \\
10 \mathrm{~K} / \mathrm{mi} 2\end{array}$ & -.075 & .061 & .015 & .089 & \\
\hline $\begin{array}{l}\text { Density > } \\
10 \mathrm{~K} / \mathrm{mi} 2\end{array}$ & -.586 & .082 & .453 & .115 & \\
\hline R2 (adj) & & & & .167 & \\
\hline $\mathrm{N}$ & & & & 19999 & \\
\hline
\end{tabular}

Bold $=$ sig. At $\mathrm{p} \leq .01$

Italic $=$ sig. At $\mathrm{p} \leq .05$ 
Table 10. Dependent Variable: Ln(Miles/Day), Reduced Form Model

\begin{tabular}{|c|c|c|c|c|c|}
\hline \multirow[b]{2}{*}{ Variable } & \multicolumn{2}{|c|}{ Total Sample } & \multicolumn{2}{|c|}{ GB } & \multirow[b]{2}{*}{ F-sig. } \\
\hline & B & S.E. & B & S.E. & \\
\hline Constant & 1.603 & .090 & & & \multirow{10}{*}{$\begin{aligned} \mathrm{All} & =.000 \\
\mathrm{~GB} & =.002\end{aligned}$} \\
\hline GB dummy & & & -.303 & .175 & \\
\hline \multicolumn{6}{|l|}{ Socio-economic } \\
\hline Female & -.176 & .042 & -.070 & .059 & \\
\hline Age $<17$ yrs & -.054 & .071 & -.135 & .097 & \\
\hline Age $17-34$ yrs & .080 & .053 & .042 & .076 & \\
\hline Age $>64 \mathrm{yrs}$ & -.467 & .075 & -.077 & .103 & \\
\hline $\begin{array}{l}\mathrm{HH} \text { inc - low } \\
\text { quartile }\end{array}$ & -.187 & .063 & -.223 & .087 & \\
\hline $\begin{array}{l}\text { HH inc }-3 \text { rd } \\
\text { quartile }\end{array}$ & .281 & .052 & -.171 & .085 & \\
\hline $\begin{array}{l}\mathrm{HH} \text { inc }-4 \text { th } \\
\text { quartile }\end{array}$ & .327 & .059 & .143 & .098 & \\
\hline Employed & .877 & .057 & -.020 & .081 & \\
\hline \multicolumn{6}{|l|}{ Urban Form } \\
\hline Not in MSA & -.023 & .082 & .031 & .158 & \multirow{5}{*}{$\begin{array}{l}\mathrm{All}=.000 \\
\mathrm{~GB}=.173\end{array}$} \\
\hline $\mathrm{MSA}<250 \mathrm{~K}$ & .084 & .088 & -.283 & .169 & \\
\hline $\begin{array}{l}\text { MSA } 250- \\
500 \mathrm{~K}\end{array}$ & .120 & .100 & -.218 & .163 & \\
\hline MSA $1-3 \mathrm{M}$ & .060 & .075 & -.185 & .156 & \\
\hline $\mathrm{MSA}>3 \mathrm{M}$ & .107 & .069 & -.354 & .160 & \\
\hline $\begin{array}{l}\text { Density }< \\
1 \mathrm{~K} / \mathrm{mi} 2\end{array}$ & .282 & .051 & -.323 & .078 & \multirow{4}{*}{$\begin{aligned} \mathrm{All} & =.000 \\
\mathrm{~GB} & =.000\end{aligned}$} \\
\hline $\begin{array}{l}\text { Density } 4 \mathrm{~K}- \\
10 \mathrm{~K} / \mathrm{mi} 2\end{array}$ & -.094 & .061 & .030 & .090 & \\
\hline $\begin{array}{l}\text { Density > } \\
10 \mathrm{~K} / \mathrm{mi} 2\end{array}$ & -.731 & .080 & .542 & .114 & \\
\hline $\mathrm{R}^{2}$ (adj) & & & & .154 & \\
\hline $\mathrm{N}$ & & & & 19999 & \\
\hline
\end{tabular}




\section{List of Figures}

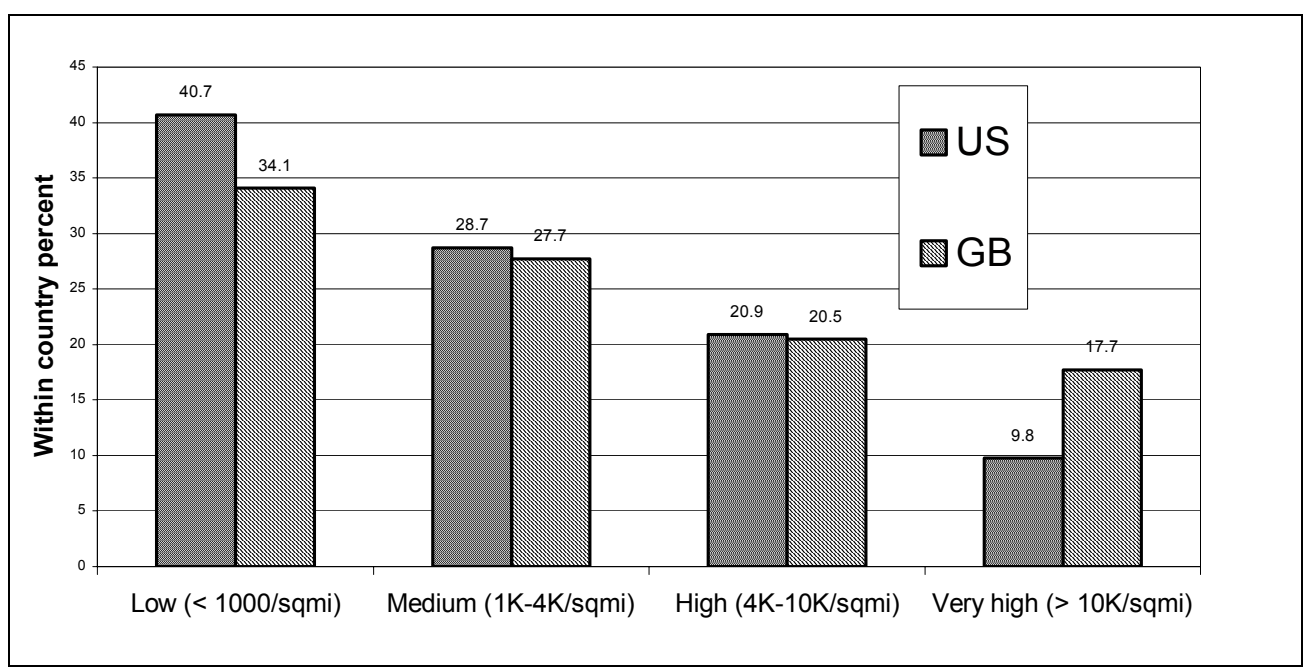

Figure 1. Population Density In Place Of Residence 


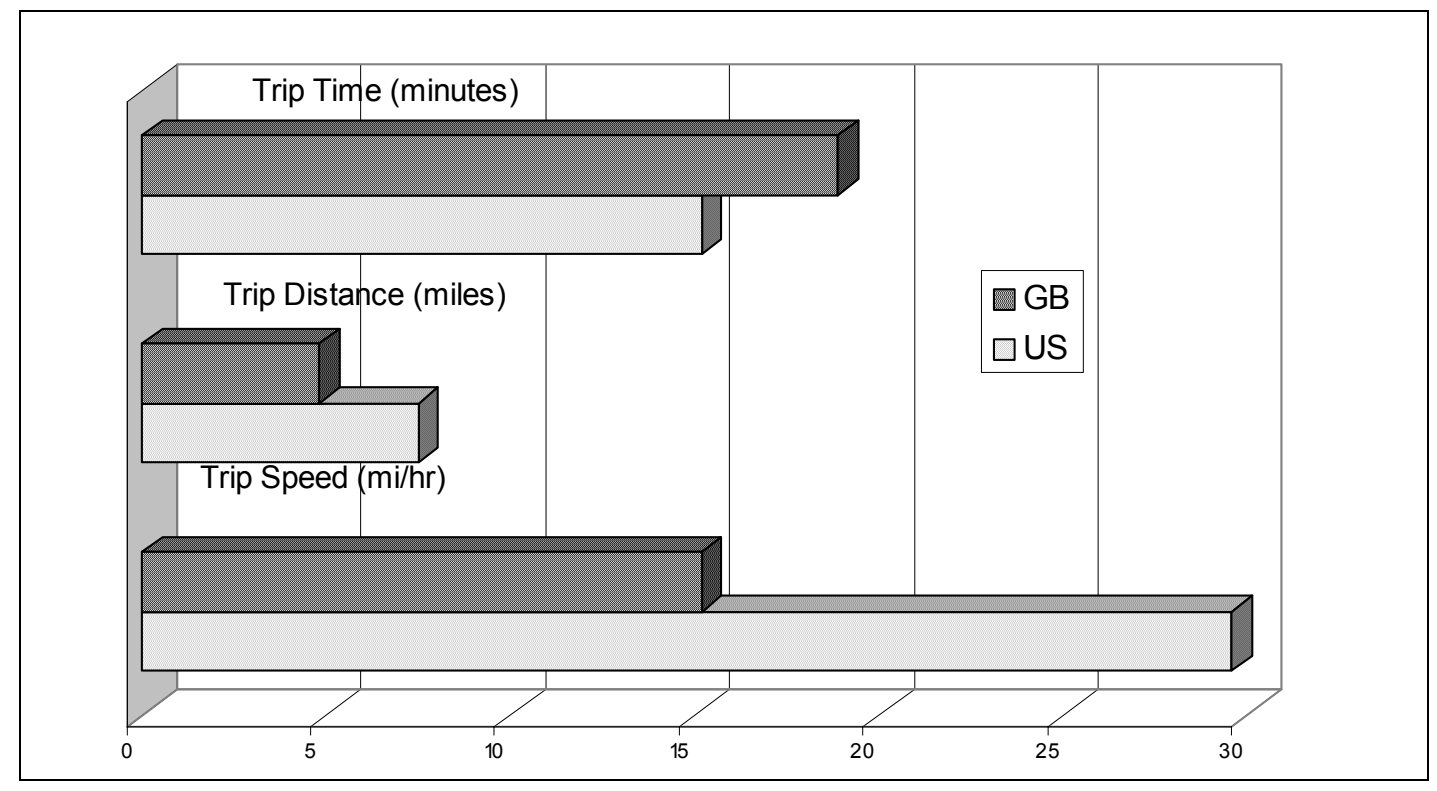

Figure 2. Average Trip Time, Length And Speed 


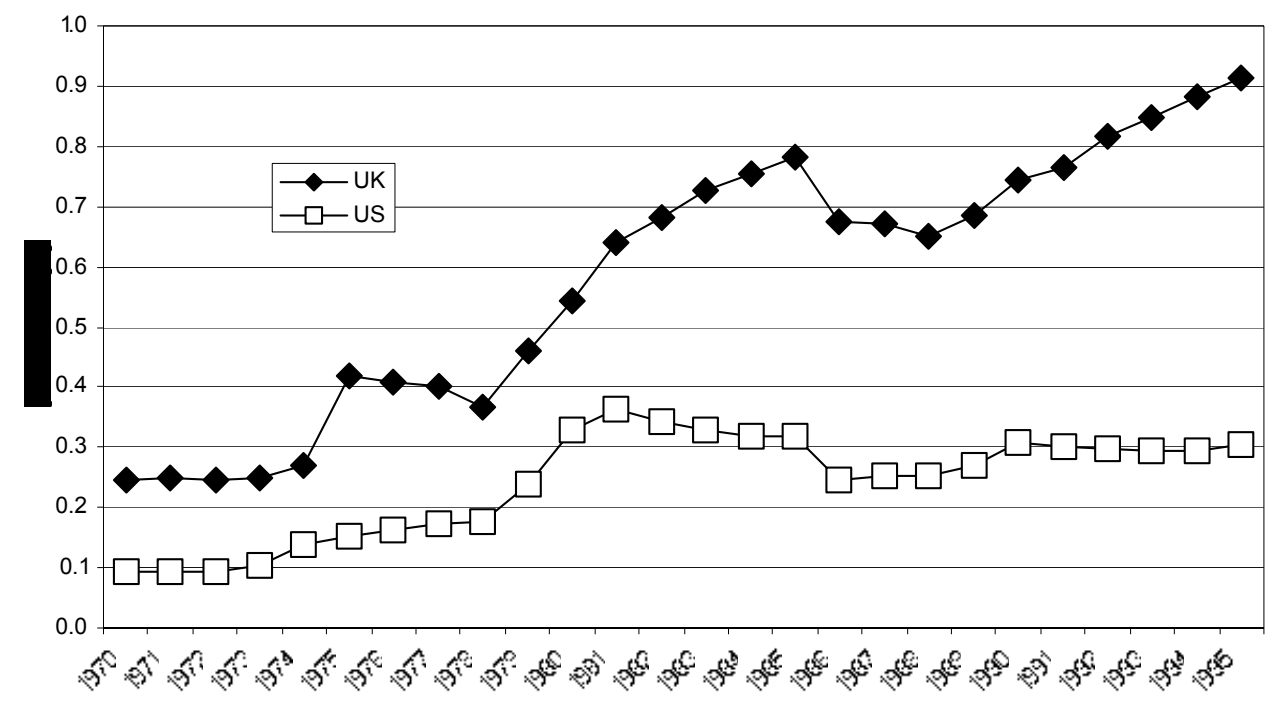

Figure 3. US AND UK Nominal Gasoline Prices 